\title{
Concerning the Apperception of Robot-Assisted Childcare
}

\author{
Raya A. Jones ${ }^{1}$ (D)
}

Received: 19 September 2017 / Accepted: 15 February 2018

(C) The Author(s) 2018. This article is an open access publication

\begin{abstract}
This essay looks askance at how robot-assisted childcare is constructed in the public domain of the Internet. Complex interactions of rhetorical manoeuvres, narratives and postnarrativity, and semiotic slippages may channel the apperception of this application of robotics. The prospect of robots in childcare roles is exceptionally contentious, for it connotes interference with the child-caregiver attachment bond. The industry's response to psychology-informed concerns is to 'rebrand' the product as a robot companion for a child or as a home robot for the family. A technocentric bias in information disseminated online creates an illusion of expertise and may endorse technology-driven morality.
\end{abstract}

Keywords Social robotics $\cdot$ Information technologies $\cdot$ Childcare

\section{Introduction}

Human experience increasingly takes place within what Floridi (2010) has termed the infosphere, offline as well as online, where the 'threshold between here (analogue, carbon-based, offline) and there (digital, silicon-based, online) is fast becoming blurred' (p. 8). Socially interactive robots come into being within this lifeworld of blurred boundaries, and increasingly differ from the androids of classic science fiction and folklore. Bots in various forms and degrees of physical embodiment are already part of everyday life. Disembodied automated response systems and internet search engines routinely configure day-to-day activities. Chatbots enter our social spaces if we let them in, and 'smart' devices (e.g. Amazon Echo) may sit on our shelves. We

Raya A. Jones

jonesra9@ cardiff.ac.uk

1 School of Social Sciences, Cardiff University, Glamorgan Building, King Edward VII Avenue, Cardiff CF10 3WT, UK 
encounter robots also vicariously through a confluence of sources ranging from movies, television dramas and documentaries, newspapers, blogs and commercial websites.

The topic of robot-assisted childcare can encompass devices ranging from smart baby monitors and robot companions (already available) to futuristic humanoids providing total care, which may or may not be technologically feasible. This essay looks askance at how the topic is constructed in the public domain of the Internet, where complex interactions of rhetorical manoeuvres, narratives and postnarrativity, and semiotic slippages may guide sense-making apropos technological innovations. In the polyphonic onslaught of informational flows, the term 'robot' acquires meaningfulness beyond the concrete referent. It becomes 'an object formed in discourse in more profound ways than being the subject of talk about machines that engineers build. The talked-about robot has semiotic properties that are not reducible to the machine's technical properties' (Jones 2016, p. 49).

The word apperception serves to emphasize that people may make sense of robots designed for assisting childcare by assimilating the idea into a body of ideas they already possess, such as beliefs about child development, good parenting, and machines. The particular labelling of the artefact (robot nanny, babysitter, companion, childcare robot, home robot) is part of its discursive construction. Such labels, however, keep the focus on the machine. Rendering the topic as robot-assisted childcare shifts the problem space. The problem is not the robot, but the necessity of its application; that is, the question is not whether robots capable of childcare tasks can be built, but whether people with childcare responsibilities need robots to assist them, and what are the long-term implications of robotic assistance for both child and caregiver. Robot-assisted childcare raises a plethora of ethical issues. Opinions are polarized. Faith in potential benefits underpins moral claims that place the onus on society to take advantage of technological progress for our children's sake whereas concerns informed by extant knowledge of child development and socialization drive moral claims that place the onus on society to safeguard our children against misuses of technology. Since the industry is in its infancy, there is no direct evidence for and against either standpoint. Consequently, the topic area is a depository of hopes, fears and even fantasies, all of which find expression in the ways that information about robots is disseminated and received.

This essay shifts the problem space again. At issue is not pros and cons of robotassisted childcare per se, but how the affordances of information and communication technologies (ICT) may channel the apperception of robot-assisted childcare ahead of any face-to-face interaction with such robots. Up to a point, this takes a cue from postphenomenology. Ihde (2008) has noted a recent 'empirical turn' in philosophy of technology, expressed in research centred on case studies and descriptive concreteness, and marked by attention to how technological materiality enters the lifeworld. Nørskov (2015) revisits Ihde's position on technological relationships through the concrete case of people interacting with each other via a teleoperated robot. In contradistinction, the present essay concerns how people may vicariously relate to (ideas of) socially interactive robots via embodied practices associated with ICT.

It is widely commented that interface technologies, which enable users to fastforward and rewind, skip, surf channels and the internet, and so forth, bring about the collapse of narrative. Rushkoff (2013) proposes that consequently the path to sense- 
making resembles an open game with no end-goal; and digital technology, as a cultural landscape, has begun profoundly to affect people's conception of themselves in relations to others and institutions. Similarly, Turkle (2011) points to society's arrival at what she calls a 'robotic moment', marked by readiness to accept robots as relationship partners, as a consequence of social media, the Internet and communication devices. New intimacies with our machines create what she terms 'tethered' lives, lived by subjects wired into social existence through technology. These observations intersect with the present issue, firstly, apropos the immediate level of accessing online information about robots and children, whereby one enters the culture of presentism and postnarrativity. The main body of the essay concerns this level of analysis. Secondly, and more speculatively, the emergence of 'tethered' lives may lead to normalization of technology-driven morality.

\section{Contours of the Controversy}

\subsection{The 'Robot Nannies' Debate}

The prospect of robots in childcare roles is exceptionally contentious, for it connotes interference with the primary and deepest relationship any human being can have. The attachment bond formed between an infant and a human caregiver is believed to set the foundation for individuals' personality development, mental health, intimate relationships and commitments in adulthood (e.g. Bowlby 1969, Ainsworth and Bowlby 1991, Schore and Schore 2008). The industry's response to concerns in this vein is to deflect from the controversy by 'rebranding' the product as a robot companion for children or as a home robot for the family (examples throughout the following).

In Britain, the topic attracted media attention first in 2008. Under the headline, 'Robot nannies threat to child care', the Daily Telegraph reported concerns raised by professor of robotics Noel Sharkey during the Cheltenham Science Festival. It could be 'all too easy to leave the kids with a robot and watch what is going on in the corner of your computer screen. ... This may be quite safe and entertaining but what kind of role model is a robot? Could this lead to a generation of social misfits?' (Sharkey, quoted in Highfield 2008). Sharkey (2008) outlined his ethical appraisal in Science (open access) and has been cited by Wired (Keim 2008), for instance. Subsequently, Interaction Studies dedicated a special issue (volume 11, number 2) to the debate. In the target article, Sharkey and Sharkey (2010) outlined an argument firmly grounded in developmental psychology — citing Bowlby's attachment theory and more - and implored policymakers to put in place statutory interventions to prevent potential misuses of robots by irresponsible parents. Several commentators concurred, but others disagreed that the risks are realistic or that such robots are technologically feasible in the near future. Although Interaction Studies is not open access, comparing this set of academic papers with the aggregate of webpages sampled in the present study throws into sharp relief some of the peculiarities of online informational flows.

The journal's special issue brought together a multidisciplinary cast of 29 writers with expertise in either child development or robotics. The debate had a distinctive 
multivoiced character not only because the participants voiced dissimilar views, but also because even convergent views were informed by different disciplinary platforms, and their proponents interacted differently with the topic (Jones 2016). Nevertheless, an overall coherence emerged, firstly, due to the fact that a shared focus of attention had been set in the target paper. The numerous 'voices' were in dialogue with each other (even when not directly addressing other writers) by virtue of agreeing or disagreeing with the Sharkeys' argument. Hence, the set of papers as a whole had the coherence of a debate. Secondly, since all the papers shared a focus, it was possible to compare their orientations. The analysis revealed thematic differences along three dimensions irreducible to each other (utopian versus dystopian leanings, factual versus speculative bases for argumentation, and technology-led versus psychology-led expositions), constituting the dimensionality of the debate as a whole (Jones 2016).

In contrast, webpages downloaded from a heterogenous array of internet sources (this study's dataset) inevitably represent different agendas, reasons and motives to tell about robots for children. These diverse 'voices' inhabit cyberspace separately from each other - a list of links collated by a search engine. In the absence of a shared issue to contend with, no clear dimensionality emerges from the aggregate. Consequently, the medium of the Internet provides little exposure to a range of alternative viewpoints about robots and children. The topic loses its dimensionality and depth of debate. Instead of dialogue across texts, there are at most instances of cross-references.

In autumn 2016, Avatar Mind launched iPal, marketing it primarily in China as a robot companion suitable for children aged 3-8 years who might spend daily a few hours alone. According to Avatar Mind's founder Jiping Wang, iPal is 'perfect for the time when children arrive home from school a few hours before their parents get off work' (quoted, e.g. in Wong 2016a and Baart 2016). British newspapers immediately linked it to the earlier controversy. The Guardian reported the launch of iPal under the headline, "This is awful": robot can keep children occupied for hours without supervision' (Wong 2016a). The quoted statement was Noel Sharkey's response to the news. The Daily Mail's headline read, 'Would you let a robot look after YOUR child? Meet iPal, the controversial child sized machine whose inventors claim it can be used as a babysitter' (Liberatore 2016). At the time, the product's official website included a page describing iPal as 'a great companion robot for kids. With its cute cartoon outlook, fine craftwork, latest natural language understanding technology, and cloud apps, it will be your child's best friend' (retrieved on 26 November 2016). By spring 2017, this page along with a few other pages of the original layout have been converted to a fastmoving slide show at the bottom of the English-language website. Its counterpart on the Chinese-language site remained prominently separate as late as September 2017 (the Chinese site too has changed when revisited in November 2017). The revision of English-language promotion of iPal may reflect, in part, an expansion of its range of commercial applications (advertised on the revamped site). Nevertheless, the careful selection of which content to retain and which to remove seems consistent with a 'damage-limitation' reaction to criticisms in the Anglophone world. The critics raised concerns about remote monitoring of children left home alone. Subsequently, a webpage declaring that 'when parents are away, they can use their phone to remotely control $\mathrm{iPal}^{\mathrm{TM}}$, monitor their child's safety and well-being, and video chat with him from anywhere and at any time' (retrieved on 26 November 2016) has been removed 
from the English site, though its Chinese counterpart was still prominently available in early autumn 2017 (gone by November).

\subsection{Semiotic Slippage and Rhetorical Redirection}

The juxtaposition 'robot nanny' throws us into confrontation with the unknown - a future of human-robot coexistence - whilst keeping us fixated on the maternal role of a child's caregiver, traditionally the mother or a surrogate female. This semiotic slippage in Sharkey and Sharkey's (2010) title 'The Crying Shame of Robot Nannies', following the Telegraph's 2008 headline ('Robot nannies threat...'), could be construed as a sideeffect of an innocuous attempt to create an audience-grabbing title. Nevertheless, it conjures a surrogate humanoid, an android Mary Poppins. Insofar as notions of such an artefact are readily dismissible as technologically unrealistic, the semiotic slippage detracts from the realistic likelihood that busy parents might become over-reliant on remote monitoring of infants who are effectively left alone for long periods. It is not necessary to personify the gadgets as 'nannies' or 'babysitters' in order to raise these concerns; and the artefacts themselves do not need to be humanoid. For instance, Aristotle by Nabi, which was advertised in January 2017 as a 'smart baby monitor', is a featureless speaker and camera set. Direct promotions were no longer available by spring 2017; but according to specifications quoted in a Daily Mail article dated earlier, Aristotle could 'automatically recognize when a baby wakes up, and sooth them to sleep with a lullaby, white noise, a favourite song ... Log dirty diapers and feedings. Automatically order more diapers and/or formula. ... Answer questions until your child falls asleep. Play guessing games with kids ... Read aloud from a selection of thousands of children's books', and more (Liberatore 2017). Such a device might seem to liberate parents from parenting chores, but it also removes the parent from 'bonding' opportunities created in routines such as bedtime stories, playing games, and answering the child's questions, let alone cuddling the baby whilst singing or storytelling.

The industry continues to develop robots with 'childcare' applications, but the unfavourable comments that such robots received in 2008-2010 may have affected marketing strategies at least in the Anglophone world. Whereas earlier, NEC (2005) announced the introduction of so-called 'Childcare Robot PaPeRo', companies introducing similar devices more recently tend to call them 'robot companions' or 'home robots', leaving any references to childcare-related functions to the small print. The promise of a companion for the child positions the robot as a peer, 'someone' with whom the child may bond as with another child. This could be cynically construed as a ploy to lull parents into feeling that their child is not alone when playing with a robot. Since a peer companion is not meant to replace a parent, this labelling effectively deflects from the 'robot nannies' controversy without addressing the concerns about robot-assisted childcare. Nevertheless, a 'companion' implies one-to-one relationship. One readily imagines a child with a robot instead of another child or an adult. Marketing the device as a 'home' robot further distances the product from the controversy. For instance, aiming primarily at the American market, Mayfield Robotics has promoted Kuri as a versatile home robot that could become a member of the family, like a pet. Although some of Kuri's functions parallel iPal's (e.g. remote monitoring, reading a book to the child), its promotion as something for the home-an appliance on par with a television - avoids suggesting that it is meant to assist parenting. 


\subsection{Presentism and Timeliness}

Sampling informational flows on the internet is like a dip in the proverbial river. Just as one cannot enter the same river twice, we see a snapshot only of what is online at the moment. At the same time, unarchived articles and fragments of past contents that have migrated to other websites remain present as if timeless, qualitatively indistinguishable from new or modified contents even when dates of editing are provided.

Presentism definable as an attitude that uncritically imposes current values and preoccupations underpins the construal of this topic's timeliness or, in rhetorician terminology, its kairos (opportune moment). Lately, automation of the workforce has dominated the news. Concerning iPal, the Guardian headline in September 2016 ('This is awful'...) is followed with the exposition, 'A child-size robot designed to take on distinctly adult responsibilities takes the debate over the automation of human jobs to the next level' (Wong 2016a). Reiterating Noel Sharkey's comments apropos PaPeRo in an earlier report (Wong 2016b) and acknowledging that child-robot interaction is ethically more fraught than robots in the workforce, Wong (2016a) nonetheless embeds the former in the latter, commenting that 'Childcare has rarely, if ever, been a particularly well-remunerated or respected job, but it is essential'. Put colloquially, if you are worried about robots replacing workers in major industries, consider also the consequences in this marginalized sector of the workforce, where replacing humans with robots could have dire consequences. This drift to another controversy is accentuated by Baart (2016) in a blog article about iPal: 'The mechanic babysitter raises concerns regarding the consequences of using robots to raise our children, simultaneously highlighting the debate about the automation of human jobs. ... Robot employment to childcare will lead to "a number of severe attachment disorders that could reap havoc in our society", (quoting Sharkey, originally in Wong 2016b). Arguably, the "havoc in society' that Sharkey foresees is due to psychological damage to a generation raised by gadgets, not loss of jobs.

Whereas the prospect of automation fuels worries about unemployment in the West, in Japan robotics promises solutions to workforce shortages. Under the headline, 'Robotics makes baby steps toward solving Japan's child care shortage', a Japan Times English-language article describes RoHo as a robotic care system that could be ready for a trial run by summer 2016 and full-scale implementation in 2018 (Bishop 2016a). There is an artist's realistic image of a sentinel drone guiding a cart of preschool children across a street. The article provides a wealth of information about the project, such as a specified location, naming and quoting the team leader. Google searches did not yield any independent corroboration of the RoHo project or the existence of its named leader. While the article has the trappings of a well-researched report published in a credible newspaper, closer scrutiny of the webpage reveals that it was published on April the 1st and that the sidebar tags include April fool's day. Fake news about robots might be a harmless hoax, but nevertheless contribute to informational flows. At a cursory glance, it is difficult to distinguish the above from a Japan Times article published in September 2017 (Martin 2017), which reports about a project testing a specially designed robot at a nursery school, again with an emphasis on alleviating the burden on overworked nursery school teachers amidst a nationwide staffing shortage. Less outlandishly than drones leading young children across streets, this robotic care system could monitor infants' heart rate, breathing and body temperature during naps in 
the nursery, and alert staff to any abnormalities. A named advisor to the project (Nobuaki Nakazawa) is real. However, unless we happen to be interested in following specific projects and therefore are concerned with their veracity, both the aforementioned articles equally feed into appraisals of robot-assisted childcare.

ICT-mediated presentism blurs boundaries not only between past and present but also between the technologically feasible and the imaginatively plausible. Bishop (2016a) may give food for thought even when we take it to be a hoax. The article is followed with a link to a survey inviting readers to rate the idea of androids looking after children. On 11 April 2016, Japan Times republished the article in its 'language' section (with the caveat that it was originally published on April's fool day) under the title, 'Let's discuss using robots in child care', along with a lesson plan (Bishop 2016b).

\section{The Technological Imagination}

\subsection{Fault Lines}

The technological imagination, as termed in Jones (2016), paraphrases C. Wright Mills' definition of the sociological imagination. Whereas the sociological imagination is a stance that interprets social phenomena in terms of what these reveal about the workings of a society, the technological imagination interprets social issues in terms of what technology can do for society and persons. These alternative perspectives feature in robotics as two camps at loggerheads about how to steer the technology. As Herik et al. (2011) put it, the 'society-driven side opines that the world is driven and run by social aspects', and is concerned with 'safety, security and supervision'; the 'technology-driven side tells that the world is driven and run by technological developments, and that robots are here for further enhancements and new applications', and measures progress in terms of innovation (p. 107). This fault line runs also through the discourse of robots for children. However, while the schism was clear in the robot nannies' debate in Interaction Studies (cf. Jones 2016), it is diffused in the public domain. The diffusion reflects the mundane fact that, online, differing viewpoints are expressed across unconnected contexts, with different agendas or reasons for informing about robots for children, and likely with different audiences (as opposed to a specialist academic journal providing a platform for the debate). Less trivial is the finding that psychology-informed appraisals of robot-assisted childcare, and of robots for children in general, are scarce.

An article posted in a blog associated with the Institute of Electrical and Electronics Engineers (IEEE) under the title, 'Robot nannies: should gadgets raise your kids?' (Chant 2017) appraises risks ensuing from potential abuses of technology. It includes an interview with the vice president of the IEEE Society on Social Implications of Technology, Jim Isaak, who points out that devices such as Kuri and Aristotle could be hacked, enabling strangers to watch the child, or might be used to sell products to young children. Listing ethical concerns, Isaak identifies scenarios likely to raise issues of legal responsibility; for instance, 'If a robot accidently hurts a child, how will this be handled in court? Conversely, how should the robot respond if it witnesses child abuse in the home?' While these are pertinent issues, conspicuously absent in his appraisal are concerns about psychological risks to children raised by gadgets. Cautionary notes such 
as Isaak's are society-driven in accordance with Herik et al.'s (2011) characterization, but would be classed as technology-led following Jones' (2016) analysis of the robot nannies debate.

In the latter context, irrespective of whether particular writers promoted or contested the idea of robot nannies, psychology-led arguments emphasized a basis in knowledge of child psychology, and called for evaluating risks and benefits of robot-assisted childcare on that basis. Technology-led arguments emphasized understanding the technology, and evaluated its capacity to deliver childcare. In the present dataset, technology-driven texts tend to inform about progress, either introducing specific gadgets or reviewing the state of the art regarding robots and children (not necessarily 'childcare' robots). An article published on Forbes website under the headline, 'Could your child's best friend be a robot?' (Yao 2017) describes how much children enjoyed interacting with social robots in an exhibition. The writer, Mariya Yao, is the head of $\mathrm{R} \& \mathrm{D}$ in an AI and bots firm; she is clearly passionate about this technology. Her answer to the headline question is unconditionally affirmative, and her enthusiasm 'sells' us the notion that children love robots and therefore should have robot companions: 'Robots captured the hearts of children long before they stirred the imagination of Silicon Valley. ... Technology pioneers in robotics, artificial intelligence, and character design have turned childhood fantasies into reality' (p. 1). Yao quotes roboticist Cynthia Breazeal, who believes that 'technology should "prioritize the unique needs of a human being" by having a highly interactive and "empathetic presence." (p. 2). In other words, social robots differ from other devices by virtue of being equipped with algorithms for face and voice recognition, and for interactional reciprocity ("empathetic' responses). Biologically inspired design allows the machine to mimic how people naturally interact with each other. To say that these machines 'prioritize' the 'unique needs' of human beings, however, is fundamentally different from saying that a mother prioritizes her child's unique needs.

\subsection{Do Children Need Robot Friends?}

The above question is posed rhetorically. If it is answered in earnest, either yes or no, one's answer would reflect personal values and beliefs rather than evidence-based reasoning. Children's fascination with robots encountered in an exhibition or other brief encounters should be taken with circumspection. Longitudinal studies indicated that users of commercially available robots typically spent less than a combined total of $10 \mathrm{~h}$ with the robot before losing interest (Tanaka et al. 2007), and likewise studies that placed robots in schools often found that children grew bored with a robot after a few sessions (cf. Jones 2016). Roboticists usually tackle this 'glitch' by adding novel features to the robot so as to rekindle children's interest. The question, do children actually need robots, is sidestepped.

The technological imagination hears the query, could a robot be your child's best friend, as an inquiry about the machine's capacity to do what it is designed to do. For instance, an ipalrobot.com page that in autumn 2016 featured prominently on the English-language website bore the title, 'A Friend to Play With' followed with the information that ' $\mathrm{iPal}$ has 25 motors that enable it to make intricate human-like movements. It has a 3 watt per channel sound system for high quality music. Your child will enjoy its dancing and music, and its ability to play fun games' (retrieved on 26 
November 2016; it has since been incorporated into the home page slide show). The depiction of a robot as a friend can be stretched too far for Western sensibilities, however. Originally, Avatar Mind claimed that iPal 'is not a cold, unfeeling machine, but ... is happy when your child is happy, and encourages your child when he is sad' (retrieved on 23 October 2016). Shy of a year later, the only trace of this statement can be found in independent articles, dated to autumn 2016, that have quoted it. Avatar Mind leaves us with the assurance that $\mathrm{iPal}$ has been developed by robot experts 'with deep experience in artificial intelligence, motion control, sensors and power management technologies' (retrieved 19 September 2017). Sceptics may note the absence of experts in child psychology who may advise about the desirability of having a machine for a friend.

\subsection{Illusion of Expertise}

The present dataset is skewed towards the technology-driven. Quantitatively, this may simply reflect a confluence of circumstantial factors, such as commercial promotion of new products, and the likelihood that technology enthusiasts readily blog about gadgets whereas child psychologists and psychotherapists are less likely to engage with the topic since the robots in question are not commonplace yet. As a result, however, the informational flow takes on the appearance of trending. McKenna and Bargh (2000) pointed to a fallacy peculiar to the internet, which they termed the illusion of large numbers, whereby people might grossly overestimate how many others share their views, and consequently not realize that their beliefs differ from the mainstream. Similarly, an illusion of expertise may apply with respect to the present topic, whereby a technocentric construal of robots for children is mistaken not only for a majority view, but also for expert opinion.

Categorical statements made by roboticists insinuate a basis in expertise that allows them to predict social-developmental outcomes with the same confidence that Avatar Mind can aver that iPal is equipped with cutting-edge technology. Psychologists who are professionally qualified to advise on child socialization and mental health are seldom consulted in technology-driven expositions. The level of detail and factual grounding in product specifications or reports of specific research projects may also feed the illusion of expertise. In contrast, given the current absence of directly relevant empirical evidence, misgivings about robot-assisted childcare are by necessity expressed in the generalized manner of a plea to common-sense, which at best can be grounded in psychological theories articulated many decades ago in a predigital world. When occasionally technology news and blogs tell about psychologists' investigations into child-robot interactions, the emphasis is on 'testing' the benefits of using robots in education or (e.g.) with autistic children, thus creating the impression that psychologists across the board endorse robots for children.

An article published in a blog associated with NBC News under the heading, 'Let robots teach our kids? Here's why that isn't such a bad idea' (Bennington-Castro 2017) promotes robots for preschool children. Bennington-Castro identifies a roboticist (Henny Admoni) at Carnegie Mellon University and notes unnamed 'other experts' who reportedly 'see these machines playing a significant role in children's emotional, social, and cognitive development in the near future'. Bennington-Castro quotes also a Cornell University psychologist (Solace Shen) who investigates child-robot interactions 
in preschool settings: "“The goal is not to have the robot replace interactions with humans," she says, "But more to supplement them"”. The setting in which Shen observes child-robot interaction is significant, however. In school, children interact with a robot alongside peers and with a teacher present. At home, a busy parent might be tempted to leave a child alone with the robot.

Most articles about robots for children (e.g. the aforementioned by Yao and by Bennington-Castro) do not refer to childcare since the focus is on what the robot can do for the child in terms of fun and learning. It is a tangential debate whether robots in schools can enhance learning beyond mere edutainment. Nevertheless, positive appraisals of robots as educational aids, coupled with the illusion of expertise, may persuade parents to invest in a robot for their young child.

\subsection{Technology-Driven Morality}

The technological imagination is associated with the belief that technology is inherently benign and beneficial. The tacit narrative could be titled, Good Tech, Bad Human. Robots are good for children, and any risks lie in human factors such as neglectful parents, paedophile hackers, and unscrupulous vendors (the narrative goes). The moral message is that responsible parents ought to get a robot for their child. This moral is explicit in a Wired article bearing the headline 'Let your children play with robots' (Carmody 2010) and reporting an interview with Javier Movellan, a principal investigator in a longitudinal project that placed robots in the creche of an American university (Tanaka et al. 2007, cf. critique in Jones 2016, 2017). Asked by the interviewer, 'Why should parents let their children play with robots?' Movellan replied, 'That's easy. Parents will let their children play with robots when they see that these robots help their children become better people: stronger, smarter, happier, more sociable and more affective.' (Carmody 2010).

A leap of faith is involved in making those assertions. Movellan's aforementioned project tested robot design, and did not collect data about learning and socialization outcomes. To date, shy of a decade later, there is no scientific evidence in support of the claims he made in Wired. By the same token, there is no evidence to the contrary. We cannot tell whether generations growing up from infancy with artificial agents who can respond, learn and remember, will be better persons, better-off for it, or become lesser as humans, even an endangered species. At present, the belief that robots will help children to become 'better people: stronger, smarter, happier, more sociable and more affective' implies that children whose parents cannot afford robots will grow up worse people: weaker, duller, sadder, less sociable and less affective. It insinuates that it behoves on governments to ensure that every home and school has robots for kids. This, in turn, puts the onus on policymakers to allocate resources to social robotics. The utopian dream is thus entangled with political agendas and commercial interests.

\section{Conclusion}

At present, most people encounter socially interactive robots mainly through information about them, hence interact with objects constructed in narratives about these robots. Interface technologies are said to engender the collapse of narrative, and yet a 
'grand narrative' - according to which technological progress leads to a better worldseems to establish itself in the public domain of the Internet. It is countered with prevailing dystopian narratives, most noticeably regarding robots in the workplace. Regarding this essay's focal topic, dystopian undertones recede to the background of comments threads and 'asides' in journalistic coverage. The industry alludes to a robotic utopia and makes its promises with mythic faith in the power of technological progress.

This mythotopia unfolds against the backdrop of an imaginal landscape owed to science fiction and popular culture as much as to technological advances. In this landscape, 'robot nannies' still command critical attention through semiotic slippage, although substituting human caregivers with robots might remain confined to fiction. At present, some critics hold in mind a concept of the good-enough mother-the mother who 'in her ordinary loving care of her own baby' lays the foundations of the child's mental health (Winnicott 1964, p. 44) —and contest the industry's implicit construction of parental love, care and guidance as commodities that can be deployed by a good-enough machine. The devices poised to enter children's rooms, however, are designed to augment parents' interactions with their children, directly through video chat apps and indirectly in unilateral surveillance. Today's digital natives are already growing up wired to social existence through technology. The apperception of robotassisted childcare might well change as they become tomorrow's parents.

Open Access This article is distributed under the terms of the Creative Commons Attribution 4.0 International License (http://creativecommons.org/licenses/by/4.0/), which permits unrestricted use, distribution, and reproduction in any medium, provided you give appropriate credit to the original author(s) and the source, provide a link to the Creative Commons license, and indicate if changes were made.

\section{References}

Ainsworth, M. D. S., \& Bowlby, J. (1991). An ethological approach to personality development. American Psychologist, 46, 333-341.

Baart, R. (2016). This robot takes care of your children. Available at: https://www.nextnature.net/2016/10 /robot-nanny-adult-responsibilities/ (accessed 25 August 2017).

Bennington-Castro, J. (2017). Let robots teach our kids? Here's why that isn't such a bad idea. Available at: http://www.nbcnews.com/mach/technology/robots-will-soon-become-our-children-s-tutors-here-sn748196 (accessed 22 August 2017).

Bishop, R. (2016a). Robotics makes baby steps toward solving Japan's child care shortage. Available at: www. japantimes.co.jp/news/2016/04/01/national/social-issues/robotics-makes-baby-steps-toward-solvingjapans-child-care-shortage/ (accessed 7 September 2017).

Bishop, R. (2016b). Let's discuss using robots in child care. Available at: https://www.japantimes.co. jp/life/2016/04/11/language/lets-discuss-using-robots-child-care/\#.WbFfdHaGPIU (accessed 7 September 2017).

Bowlby, J. (1969). Attachment. New York: Basic Books.

Carmody, T. (2010). Let your children play with robots. Wired Available at: www.wired.com/2010/10 /children-robots (accessed 24 August 2017).

Chant, R. (2017). Robot nannies: should gadgets raise your kids? Available at: http://theinstitute.iee.org/ieeeroundup/blogs/blog/robot-nannies-should-gadgets-raise-your-kids (accessed 22 August 2017).

Floridi, L. (2010). Ethics after the information revolution. In L. Floridi (Ed.), The Cambridge handbook of information and computer ethics (pp. 3-19). Cambridge: Cambridge University Press.

van den Herik, H. J., Lamers, M., \& Verbeek, F. (2011). Understanding the artificial. International Journal of Social Robotics, 3, 107-109. 
Highfield, R. (2008). Robot nannies threat to child care. Telegraph Science Available at: www.telegraph.co. uk/news/science/science-news/3343667/Robot-nannies-threat-to-child-care.html (accessed 18 August 2017).

Ihde, D. (2008). Introduction: postphenomenological research. Human Studies, 31, 1-9.

Jones, R. A. (2016). Personhood and social robotics. London: Routledge.

Jones, R. A. (2017). What makes a robot 'social'? Social Studies of Science, 47, 556-579.

Keim, B. (2008). I, Nanny: Robot babysitters pose dilemma. Available at: www.wired.com/2008/12 /babysittingrobo/ (accessed 8 September 2017).

Liberatore, S. (2016) Would you let a robot look after YOUR child? Daily Mail Online. Available at: www. dailymail.co.uk/sciencetech/article-3814207/Would-let-robot-look-child-Meet-iPal-controversial-childsized-machine-inventors-claim-used-babysitter.html (accessed 19 August 2017).

Liberatore, S, (2017). Mattel unveils \$400 Aristotle AI 'nanny' speaker that can help with homework, monitor a sleeping baby and even order new diapers when you need them. Daily Mail Online. Available at: http://www.dailymail.co.uk/sciencetech/article-4085944/Mattel-unveils-400-Aristotle-AI-nanny-speakerhelp-homework-monitor-sleeping-baby-order-new-diapers-need-them.html (accessed 22, August 2017).

Martin, A. (2017). Day care facilities test robots as high-tech solution to alleviate staffing shortages. Available at: www.japantimes.co.jp/news/2017/09/07/national/day-care-facilities-turn-to-robots-as-high-techsolution-to-alleviate-staffing-shortages/\#.WbFIpXaGPIU (accessed 7 September 2017).

McKenna, K. Y. A., \& Bargh, J. A. (2000). Plan 9 from cyberspace: the implications of the internet for personality and social psychology. Personality and Social Psychology Review, 4, 57-75.

NEC (2005). NEC realizes enhanced version of its robot PaPeRo, 'PaPeRo 2005,' \& also introduces 'Childcare Robot PaPeRo'. Available at: http:/www.nec.co.jp/press/en/0503/1601.html (accessed 8 September 2017).

Nørskov, M. (2015). Revisiting Ihde's fourfold 'technological relationships': application and modification. Philosophy \& Technology, 28, 189-207.

Rushkoff, D. (2013). Permanent revolution: occupying democracy. Sociological Quarterly, 54, 164-173.

Sharkey, N. (2008). The ethical frontiers of robotics. Science, 322, 1800-1801.

Sharkey, N., \& Sharkey, A. (2010). The crying shame of robot nannies: An ethical appraisal. Interaction Studies, 11, 161-190.

Schore, J. R., \& Schore, A. N. (2008). Modern attachment theory: the central role of affect regulation in development and treatment. Clinical Social Work Journal, 36, 9-20.

Tanaka, F., Cicourel, A., \& Movellan, J. R. (2007). Socialization between toddlers and robots at an early childhood education center. Proceedings of the National Academy of Sciences of the United States of America, 104, 17954-17958.

Turkle, S. (2011). Alone together. New York: Basic Books.

Winnicott, D. W. (1964). The Child, the Family, and the Outside World. Middlesex. Penguin.

Wong, J.C. (2016a). "This is awful": robot can keep children occupied for hours without supervision. The Guardian. Available at: www.theguardian.com/technology/2016/sep/29/ipal-robot-childcarerobobusiness-san-jose (accessed 19 August 2017).

Wong, J.C. (2016b). Welcome to the robot-based workforce: will your job become automated too? Available on: www.theguardian.com/technology/2016/mar/19/robot-based-economy-san-francisco (accessed 6 September 2017).

Yao, M. (2017). Could your child's best friend be a robot? Available at: https://www.forbes. com/sites/mariyayao/2017/04/06/could-your-childs-best-friend-be-a-robot/\#5c20b5a86dbb (accessed 22, August 2017). 